\title{
Malignant melanoma of the bladder: A case report
}

\author{
Hamide Sayar, MD; Seyda Erdogan, MD; Fulya Adamhasan, MD; ${ }^{\ddagger}$ Esma Gurbuz, MD; ${ }^{*}$ Mehmet Fatih Inci, MD*
}

*Kahramanmaras Sutcu Imam University, Medical Faculty, Department of Pathology, Kahramanmaras, Turkey; ${ }^{\dagger}$ Cukurova University, Medical Faculty, Department of Pathology, Adana, Turkey; ${ }^{\circledR}$ Adana Numune Education and Research Hospital, Department of Pathology, Adana, Turkey; ${ }^{K}$ Kahramanmaras Sutcu Imam University, Medical Faculty, Department of Radiodiagnostic, Kahramanmaras, Turkey

Cite as: Can Urol Assoc J 2014;8(1-2):e54-6. http://dx.doi.org/10.5489/cuaj.1242

Published online January 14, 2014.

\section{Abstract}

Primary malignant melanoma of the bladder is very rare. Rather than being a primary lesion, malignant melanomas of the bladder are more commonly metastatic lesions. The histopathological appearance largely does not differ from that of melanoma at other body sites. It is often difficult to discriminate whether a bladder melanoma is primary or metastatic. Therefore, a careful review of histological features and performing necessary immunohistochemical staining procedures for S-100 protein and HMB-45 are very important in achieving a correct diagnosis. We report a case of hypomelanotic malignant melanoma of the bladder. Despite the variety of therapies available for primary melanomas of the bladder, the prognosis is still poor.

\section{Introduction}

Primary malignant melanoma of the bladder is very rarely seen and accounts for $0.2 \%$ of all melanomas. ${ }^{1,2}$ While the urethra and penis are the most common sites of origin of primary malignant melanoma in the genitourinary tract, the prostate, renal pelvis, ureter, and bladder are less common. ${ }^{3}$ Rather than being a primary lesion, malignant melanomas of the bladder are more commonly metastatic lesions, which originate from a distant primary site. ${ }^{4}$ Despite the variety of therapies available for primary melanomas of the bladder, the prognosis is still poor. ${ }^{1,5}$ We report a case of hypomelanotic malignant melanoma of the bladder, which mimics high-grade urothelial carcinoma.

\section{Case report}

A 70-year-old man was admitted to the Department of Urology for gross hematuria. After obtaining informed con- sent, we performed a deep transurethral resection (TUR) of the bladder. The totally resected specimen weighed $20 \mathrm{~g}$. Upon microscopic evaluation, the tumour was predominantly composed of fascicles and sheets of oval to fusiform cells (Fig. 1). Tumour cells had moderate cytoplasm and spindle-shaped hyperchromatic nuclei with conspicuous nucleoli, and had a mitotic rate of more than 10 mitoses per 10 high-power fields (HPF). The tumour tissue invaded the lamina propria and muscular layers. The overlying epithelium was eroded and focal pigmentation was close to the surface. We could not perform an immunohistochemical staining at that time because the laboratory had not yet been constructed. Pathological diagnosis of invasive malignant spindle cell tumour was reported as high-grade urothelial carcinoma. The patient was admitted urgently to our hospital with an acute abdomen 30 months after the biopsy. During laparotomy, a frozen section was obtained from the mass that occupied the abdomen. Permanent sections showed heavily pigmented malignant epithelioid-shaped melanocytes with a high mitotic rate (Fig. 2). Immunohistochemical study showed that tumour cells were positive for S-100 (Fig. 3, part A) and $\mathrm{HMB}-45$ (Fig. 3, part B), and they were negative for cytokeratin 7 and 20, actin, and desmin. These findings were consistent with malignant melanoma. Exhaustive examination of the skin, eyes, gastrointestinal tract, brain, and chest was performed to exclude other possible primary sites of origin. Computed tomography (CT) showed a giant lobulated soft tissue mass measuring $20 \times 19 \times 9 \mathrm{~mm}$ with centrally necrotized areas in the abdomen, starting from inferior pole of the liver and extending towards the pelvis and the bladder. Also, some metastatic foci were found within the abdomen (Fig. 4). A retrospective search was done to find out whether the patient had a previous biopsy in the pathology service. Transurethral resection of bladder tumour specimens were found in the archives and re-examined. In contrast to the appearance of the frozen tissue, which contained an epithelioid cell component, more than $90 \%$ of the 


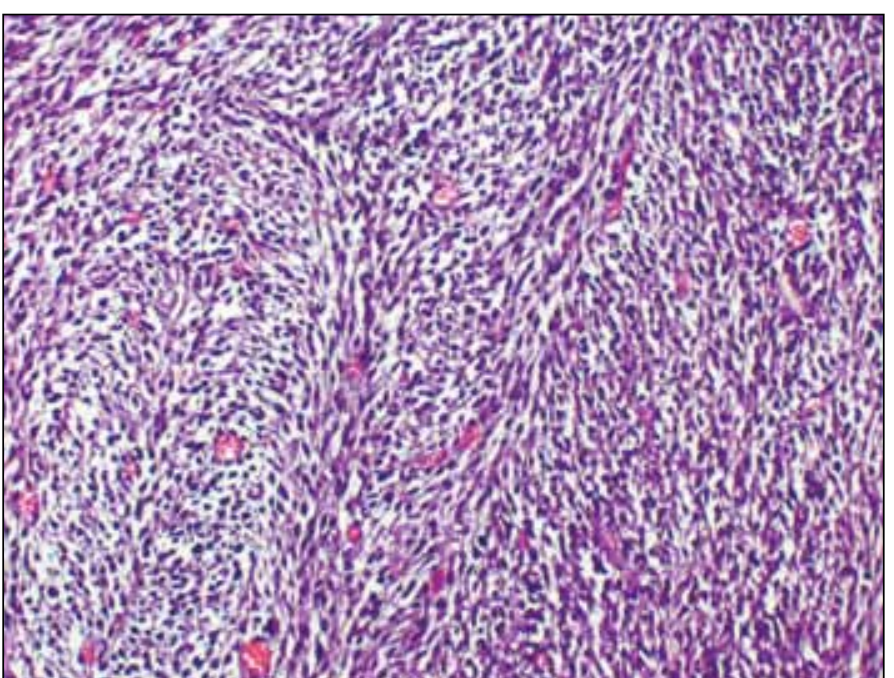

Fig. 1. Microscopic examination shows that the tumour is predominantly composed of fascicles and sheets of oval to fusiform cells (hematoxylin and eosin $\times 100)$

tumour was composed of spindle cells. Melanocytes were seen in the urothelial mucosa close to the tumour margins (Fig. 5). We found diffuse positivity when we performed HMB-45 and S-100 staining on the first TUR biopsy specimen. It was noticed that the patient had not discussed the biopsy report with the clinician. After refusing therapy, the patient died 2 months later.

\section{Discussion}

Primary malignant melanoma is uncommon in the genitourinary tract, especially in the bladder. ${ }^{4}$ Wheelock and colleagues reported the first case of primary malignant melanoma of the urinary bladder in 1942. ${ }^{6,7}$ About 20 cases of primary malignant melanoma of the bladder have been

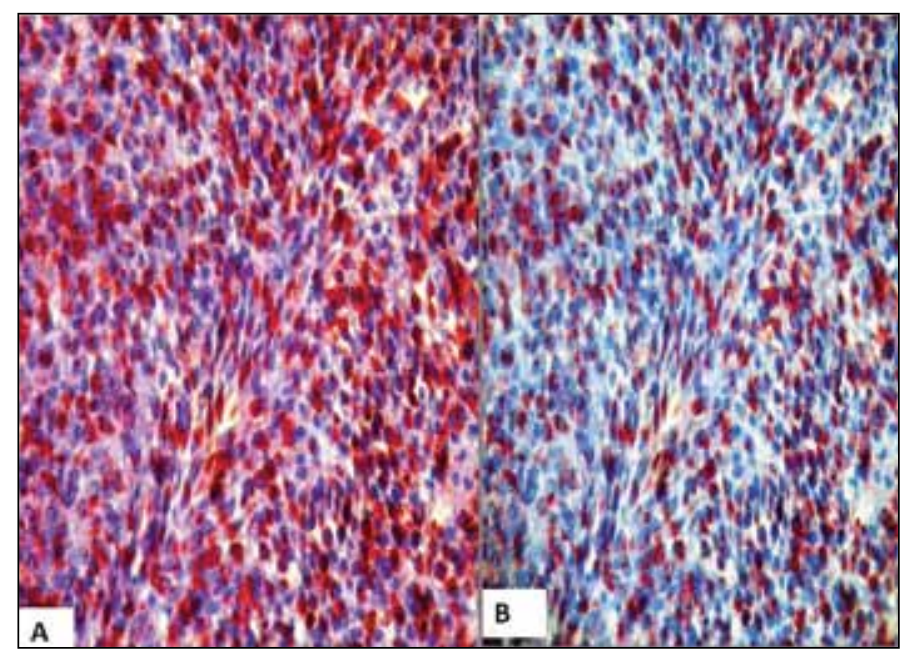

Fig. 3. Immunohistochemical staining for (A) S-100 and (B) HMB-45 in a malignant melanoma of the bladder (S-100, $\times 200$; HMB-45, $\times 200$ ).

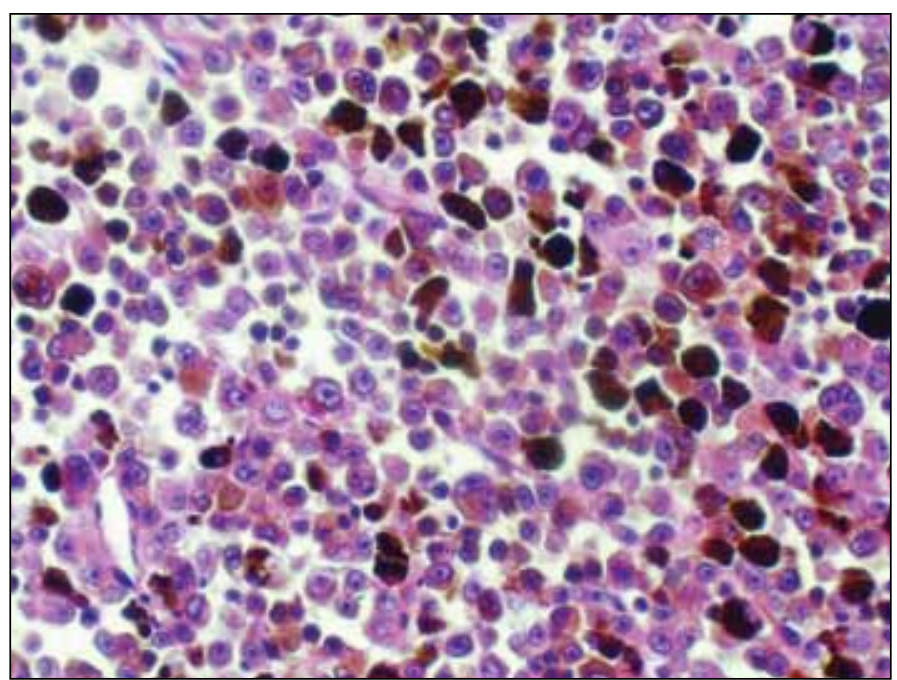

Fig. 2 The tumour cell has a large, irregular nucleus and a prominent nucleolus, with heavily pigmented melanosomes (hematoxylin and eosin $\times 200$ ).

reported to date. ${ }^{1}$ Patient ages range from 34 and 82 years (mean 60.6 years), and there was no sex predominance; the male to female ratio was $1 / 1$. Most cases presented hematuria and/or dysuria as initial symptoms. ${ }^{1}$ This was the case for our patient.

It is often difficult to discern whether a bladder melanoma is primary or metastatic. ${ }^{5}$ Some authors have proposed the following criteria for designating a bladder melanoma as a primary lesion: (1) no previous cutaneous lesion history; (2) no evidence of regressed cutaneous malignant melanoma; (3) no evidence of other visceral primary melanoma; (4) the pattern of recurrence should be consistent with the initial lesion; and (5) the margins of the bladder lesion should

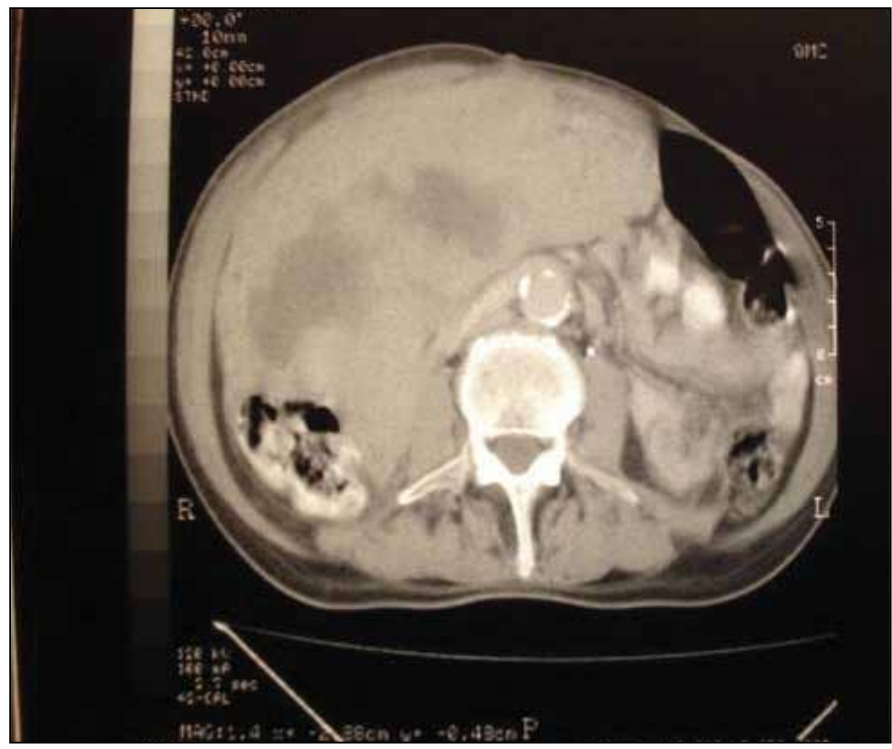

Fig. 4. The computed tomography scan shows centrally necrotized areas in the abdomen, starting from inferior pole of the liver and extending towards the pelvis and the bladder. 


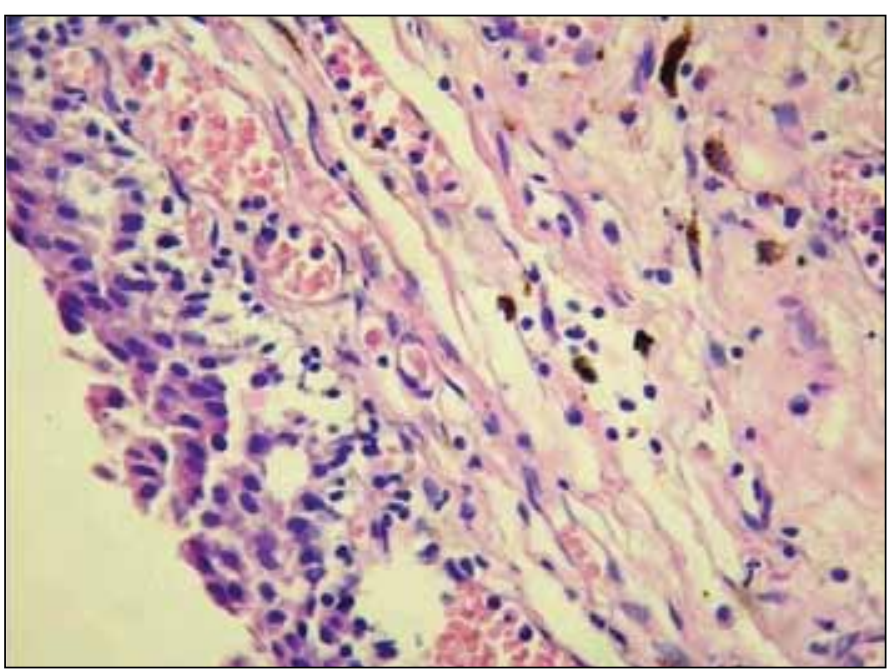

Fig. 5. Histological section of the bladder wall demonstrating pigmented melanocytes (hematoxylin and eosin $\times 100$ ).

contain atypical melanocytes. ${ }^{3,8}$ Our case fulfilled all these criteria, with the exception of number 4 . Metastatic tumour masses within the abdomen showed an epitheloid cell pattern containing a huge amount of melanin, in contrast to bladder melanoma. The origin of malignant melanoma in the bladder remains unclear. The existence of atypical melanocytes on the mucosa surrounding the tumour supports the ectopic melanocyte theory. ${ }^{2}$ According to this theory, precursor melanocytes arise in the neural crest and migrate to the bladder. ${ }^{2,3,8}$ Another theory is that argyrophil urothelial cells are derived from urothelial stem cells with differentiation in the direction of neoplastic melanocytes. ${ }^{2,6,9}$ In our case, pigmented melanocytes around the tumour supported the primary origin.

Because malignant melanoma has microscopic variability, it can be epithelioid, spindle-shaped, or extremely bizarre. Specifically, these lesions may mimic urothelial carcinoma on histological evaluation, particularly with cases of hypomelanotic to amelanotic melanoma. ${ }^{10}$ In our case, pathological examination showed a solid lesion that closely mimicked urothelial carcinoma. Its true nature became obvious only after high-power examination and the finding of fine brown granules in some tumour cells. Most previously reported cases of primary bladder melanomas showed a strong pigmentation. ${ }^{1,2-9}$ In our case, the pigment was very scant, similar to what had been found in the case of Ahlen and colleagues. ${ }^{11}$ In such cases, immunohistochemical study is required. The immunohistochemical markers S- 100 protein and HMB-45 antigen have become an important component of diagnosis. ${ }^{12}$ In our case, the primary tumour and metastatic tumour were evaluated using S-100 and HMB-45.

Despite the variety of therapies available for primary melanomas of the bladder (transurethral resection, partial cystectomy, total cystectomy with urinary diversion, chemotherapy, radiation therapy, and immunotherapy with inter- feron-alpha), the prognosis of patients with this tumour is still poor. ${ }^{1,11}$ Most patients died due to widespread metastases 3 years after the initial diagnosis. ${ }^{1}$ One 1 patient survived for 144 months. ${ }^{13}$ Although we did not apply any treatment, the patient survived longer than average. He died due to metastases 30 months after the first TUR biopsy.

\section{Conclusion}

Malignant melanoma in the bladder is very rarely seen. It must be kept in mind that we may witness malignant melanoma, particularly the hypomelanotic type, in the urinary bladder. Therefore, a careful review of histological features and performing necessary immunohistochemical staining procedures for S-100 and HMB-45 are very important in achieving a correct diagnosis.

Competing interests: Dr. Sayar, Dr. Erdogan, Dr. Adamhasan, Dr. Gurbuz and Dr. Inci all declare no competing financial or personal interests.

This paper has been peer-reviewed.

\section{References}

1. Pacella M, Gallo F, Gastaldi C, et al. Primary malignant melanoma of the bladder. Int J Urol 2006;13:6357. http://dx.doi.org/10.1111/j.1442-2042.2006.01375.x

2. De Torres I, Fortu- MA, Raventos A, et al. Primary malignant melanoma of the bladder: Immunohistochemical study of a new case and review of the literature. J Urol 1995; 154:525-7. http://dx.doi.org/10.1016/ S0022-5347(01)67094-0

3. Stein BS, Kendall AR. Malignant melanoma of the genitourinary tract. J Urol 1984;132:859-68.

4. Tainio HM, Kylmälä TM, Haaspalo HK. Primary malignant melanoma of the urinary bladder associated with widespread metastases. Scand J Utol Nephrl 1999;33:406-7. http://dx.doi. org/10.1080/003655999750017086

5. Lee SH, Chang ED, Lee EJ, et al. Primary malignant melanoma of the urinary bladder: A case report. Korean J Pathol 2010;44:216-9. http://dx.doi.org/10.4132/KoreanJPathol.2010.44.2.216

6. Koijma T, Tanaka T, Yoshimi N, et al. Primary malignant melanoma of the urinary bladder. Arch Pathol Lab Med 1992;116:1213-6.

7. Khalbuss WE, Hossain M, Elhosseiny A. Primary malignant melanoma of the urinary bladder diagnosed by urine cytology: A case report. Acta Cytol 2001;45:631-5. http://dx.doi.org/10.1159/000327878

8. Ainsworth AM, Clark WH, Mastrangelo $M$, et al. Primary malignant melanoma of the urinary bladder. Cancer 1976;37:1928-36. http://dx.doi.org/10.1002/1097-0142(197604)37:4<1928::AlDCNCR2820370444>3.0.C0;2-W

9. Anichkov NM, Nilonov AA. Primary malignant melanomas of the bladder. J Urol 1982;128:813-5.

10. Radhi JM. Urethral malignant melanoma closely mimicking urothelial carcinoma. J Clin Pathol 1997;50:250-2. htrp://dx.doi.org/10.1136/icp.50.3.250

11. Van Ahlen H, Nicolas V, Lenz W, et al. Primary melanoma of urinary bladder. Urology 1992;40:550-4. http://dx.doi.org/10.1016/0090-4295(92)90414-R

12. $X_{U} X$, Chu AY, Pasha TL, et al. Immunoprofile of MITF, tyrosinase, melan-A, and MAGE-1 in HMB45-negative melanomas. Am J Surg Pathol 2002;26:82-7. http://dx.doi.org/10.1097/00000478-20020100000010

13. Garcia Montes F, Lorenzo Gomez MF, Boyd J. Does primary melanoma of the bladder exist? Actas Urol Esp 2000;24:433-6. http://dx.doi.org/10.1016/S0210-4806(00)72477-6

Correspondence: Dr. Hamide Sayar, Assistant Professor, Kahramanmaras Sutcu Imam University, Medical Faculty, Department of Pathology Kahramanmaras, Yörükselim Mah. Hastane Cad. No: 32, 46050 Kahramanmaraş, Türkiye; fax: +90 344221 23 71; hamide1976@yahoo.com 